\title{
EFEKTIVITAS PERAWATAN UNIT BOILER: STUDI KASUS DI PT. BEURATA SUBUR PERSADA
}

\author{
Maidi Saputra*1, Redha Kurniawan², Al Munawir ${ }^{3}$ \\ 1,2,3 Program Studi Teknik Mesin Fakultas Teknik \\ Universitas Teuku Umar, Kampus Alue Peunyareung, Aceh Barat, Aceh \\ 1e-mail: maidisaputra@utu.ac.id \\ ${ }^{3}$ e-mail: almunawir@utu.ac.id
}

\begin{abstract}
Abstrak
Boiler atau ketel uap merupakan alat digunakan untuk menghasilkan uap yang digunakan pada berbagai keperluan di pabrik kelapa sawit. Pada sebuah sistem ketel uap (boiler), kesiapan dan penkondisian alat perlu diperhatikan agar memenuhi target produksi yang telah direncanakan. Perawatan khususnya pada sebuah unit boiler merupakan hal yang harus sangat diperhatikan dan penting untuk dilaksanakan. Penelitian ini bertujuan untuk mendapatkan gambaran tentang perawatan unit ketel uap (boiler) di PT. Beurata Subur Persada. Peneltian ini menggunakan beberapa metode dalam mendapatkan hasil yang diinginkan, diantaranya adalah pengumpulan data secara deskriptif/interview dilapangan. Dari pengamatan dan proses wawancara dengan pihak PT. Beurata Subur Persada, maka perencanaan proses perawatan yang sesuai dengan kondisi pabrik adalah perawatan terencana (planned maintenance).
\end{abstract}

Kata kunci: Boiler, Pabrik kelapa sawit, Perawatan, perawatan terencana, PT. Beurata Subur Persada

\begin{abstract}
A boiler is a tool used to produce steam that is used for various purposes in palm oil mills. In a boiler system, the readiness and conditioning of the equipment are considered to meet the planned production targets. Maintenance, in particular on a boiler unit, is something that must be considered and essential to implement. This study aims to get an overview of the maintenance of the boiler unit at PT. Beurata Subur Persada. This research uses several methods in getting the desired results, including descriptive data collection/field interviews, from the observation and interview process with PT. Beurata Subur Persada, the planning of the maintenance process by factory conditions, is planned maintenance.
\end{abstract}

Keywords: Boiler, Palm oil mills, Maintenance, Planned maintenance, PT. Beurata Subur Persada

\section{PENDAHULUAN}

Boiler atau ketel uap merupakan alat digunakan untuk menghasilkan uap yang digunakan pada berbagai keperluan di pabrik kelapa sawit. Boiler ini salah satu komponen utama dan sangat penting dalam kelangsungan proses produksi di PT. Beurata Subur Persada[1]. 
Fungsi boiler yang utama adalah menghasilkan uap yang digunakan dalam proses perebusan (sterilizer) pada olahan kelapa sawit dan juga digunakan dalam proses pemurnian minyak (klarifikasi) kelapa sawit mentah (CPO). Selain dari fungsi diatas tersebut, satu unit boiler di pabrik kelapa sawit juga digunakan untuk menghasilkan energi listrik yang digunakan untuk menunjang proses produksi dan keperluan rumah tangga lainnya[2].

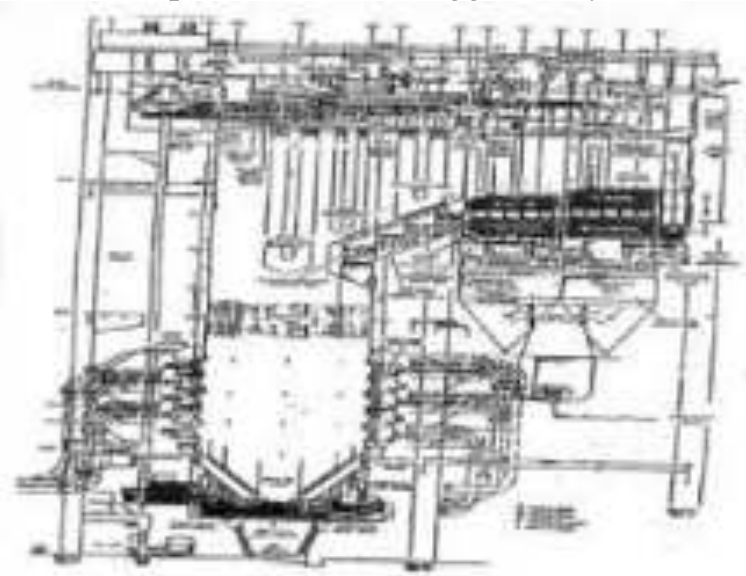

Gambar 1. Penampang boiler secara umum.

Pada sebuah sistem ketel uap (boiler), kesiapan dan penkondisian alat perlu diperhatikan agar memenuhi target produksi yang telah direncanakan[2]. Efesiensi yang baik perlu dijaga pada sebuah ketel uap (boiler), dengan cara melakukan inspeksi dan pengecekan secara berkala terhadap komponen-komponen didalam boiler[3]. Kerusakan-kerusakan atau faktor-faktor penurunan performa dari ketel uap (boiler) dapat terjadi seperti adanya pembentukan terak-terak atau kotoran-kotoran yang tersisa didalam pipa-pipa didalam boiler tersebut[4]. Pembentukan kotoran-kotoran tersebut dapat menjadi penghambat bagi panas dalam memanaskan air baku yang diubah menjadi uap, sehingga panas tidak terdistribusi dengan baik dan bisa kemungkinan terjadi kelebihan panas pada salah satu sisi boiler[2]. Kemudian dari pada itu, sebuah boiler juga berfungsi sebagai alat vital dalam sebuah pabrik pengolahan minyak mentah kelapa sawit (CPO). Untuk menjaga kualitas dan jumlah produksi dari sebuah pabrik kelapa sawit tersebut, sebuah unit boiler harus mampu menghasilkan uap sesuai dengan kebutuhan pabrik dalam mencapai target produksi[5]-[7].

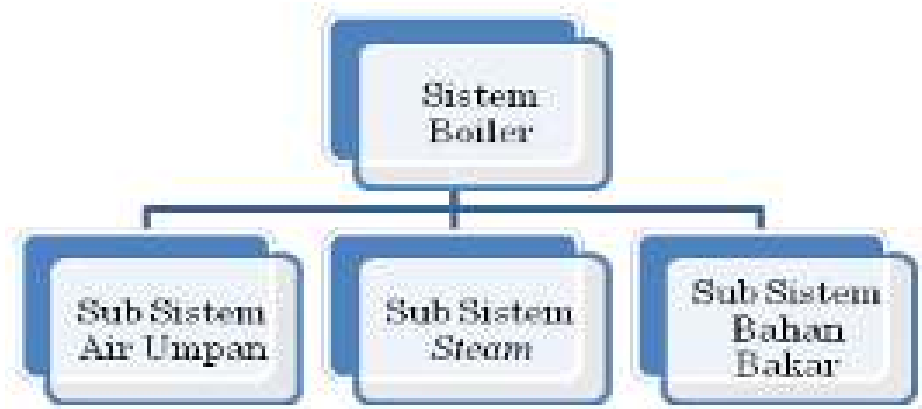

Gambar 2. Kinerja boiler.

Perawatan khususnya pada sebuah unit boiler merupakan hal yang harus sangat diperhatikan dan penting untuk dilaksanakan. Perawatan dilakukan sebagai upaya untuk menjaga atau sebuah tindakan untuk menjaga dan memelihara sebuah unit, seperti boiler pada pabrik kelapa sawit. Perawatan juga dapat berfungsi sebagai langkah awal dari perbaikan sebuah unit atau alat, sehingga dapat mencapai kondisi prima dalam menjalankan fungsinya[8], [9]. Kemudian sebuah unit boiler merupakan sebuah faktor sangat penting dalam proses produksi di pabrik kelapa sawit, ketergantungan terhadap sebuah unit boiler tersebut bisa 
mencapai $80 \%$ dari total semua alat yang dipakai. Kualitas uap yang dihasilkan cukup memberikan pengaruh yang signifikan terhadap kualitas produk yang dihasilkan, sehingga apabila batas minimum persyaratan uap yang mesti dihasilkan berkurang akan berakibat tidak baiknya hasil yang dihasilkan serta tentunya akan sangat merugikan pihak perusahaan[10].

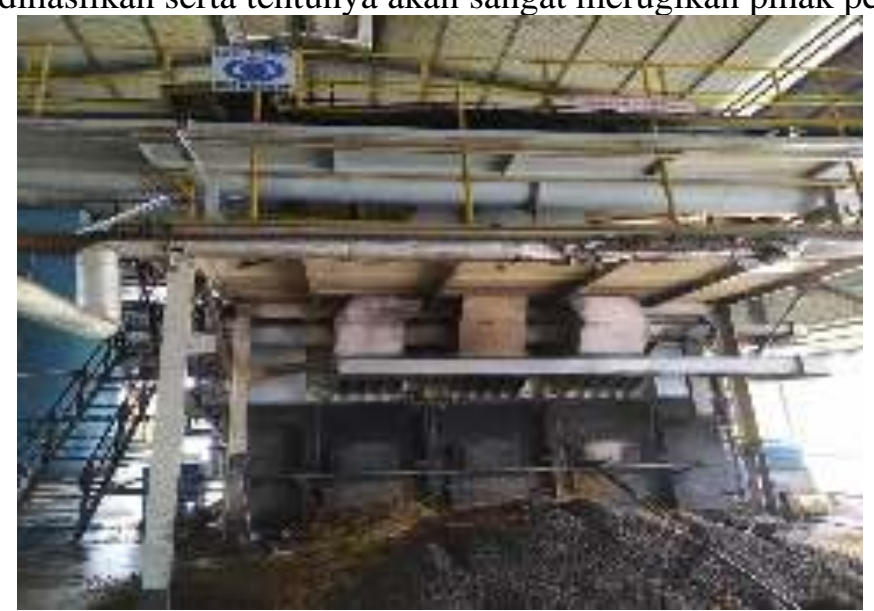

Gambar 3. Unit Boiler di PT. Beurata Subur Persada.

Perawatan boiler pada sebuah pabrik kelapa sawit bisa digunakan dengan berbagai macam metode, seperti metode perawatan preventif (preventif maintenance). Perawatan jenis ini dilakukan sebagai dasar untuk menjaga dan menilai kelayakan sebuah unit ketel uap (boiler). Perawatan boiler dimaksudkan untuk menjaga kondisi peralatan (boiler) selalu berada dalam kondisi baik dan selalu siap digunakan dalam kondisi terbaik untuk menghasilkan hasil olahan/produk yang baik. Perawatan dari ketel uap (boiler) ini perlu direncanakan dengan baik, sehingga menghasilkan hasil perawatan dan menjaga unit boiler selalu dalam kondisi baik sebelum kerusakan terjadi[2], [11].

Penelitian ini bertujuan untuk mendapatkan gambaran tentang perawatan unit ketel uap (boiler) di PT. Beurata Subur Persada. Perawatan ini bertujuan untuk melihat dan menjaga kondisi unit ketel uap (boiler) berada dalam kondisi baik pada saat pengoperasian.

\section{METODE PENELITIAN}

Peneltian ini menggunakan beberapa metode dalam mendapatkan hasil yang diinginkan, diantaranya adalah pengumpulan data secara deskriptif/interview dilapangan. Pengumpulan data secara deskirptif ini dilakukan dengan pengamatan langsung ke lapangan dan melakukan wawancara/tanya jawab kepada pihak pekerja/operator yang kebetulan bertugas pada hari tersebut. Kemudian data deskriptif ini terbagi kedalam dua kelompok data, yaitu data primer yang didapat langsung dari wawancara dan pengamatan langsung dilapangan serta data sekunder yang didapat dari pemeriksaan buku-buku laporan pabrik yang berhubungan dengan kondisi unit ketel uap/boiler tersebut. Pada akhirnya semua data-data yang telah dikumpulkan tersebut dilakukan analisa dan penarikan kesimpulan terhadap kondisi yang sedang diamati.

Metode observasi/filled research digunakan sebagai metode selanjutnya dalam pengumpulan dan mencari data-data dilapangan. Penggunaan metode ini cenderung dilakukan dengan melakukan survey-survey secara langsung ke lapangan.

Kemudian metode terakhir adalah metode kepustakaan/library research, yang dilakukan dengan cara mencari literatur-literatur tambahan yang diperlukan dalam memperkaya wawasan serta data-data yang telah dikumpulkan di lapangan. 


\section{HASIL DAN PEMBAHASAN}

\subsection{Perencanaan pemeliharaan unit ketel uap (boiler) di PT. Beurata Subur Persada}

Dari pengamatan dan proses wawancara dengan pihak PT. Beurata Subur Persada, maka perencanaan proses perawatan yang sesuai dengan kondisi pabrik adalah perawatan terencana (planned maintenance). Pada proses perawatan terencana (planned maintenance) ini dapat dilakukan dengan dua metode, yaitu preventive maintenance dan corrective maintenance. Kemudian kedua metode perencanaan ini pada saat pelaksanaannya dibagi-bagi lagi kedalam beberapa tahapan.

\subsection{Tindakan-tindakan yang dilakukan pada saat perawatan terencana}

a. Inspeksi (pemeriksaan)

Pemeriksaan dapat dilakukan terhadap unit ketel uap (boiler), untuk menyatakan atau meyakinkan apakah unit boiler tersebut berada pada kondisi siap berkerja sesuai dengan unjuk kerjanya.

\section{b. Service}

kegiatan perawatan yang dilakukan untuk menjaga unit ketel uap (boiler) selalu berada pada performance yang baik dan melihat potensi-potensi kerusakan yang mungkin terjadi.

c. Pergantian komponen

Pada proses ini, akan dilakukan pergantian pada komponen-komponen yang rusak atau dianggap sudah menurun tingkat performansinya, sehingga sangat menghambat dari kinerja boiler itu sendiri.

\section{d. Overhaul}

Tindakan ini dilakukan untuk perubahan atau perbaikan unit ketel uap (boiler) secara lebih mendasar atau banyak komponen yang diperbaiki. Tindakan overhaul ini biasanya dilakukan secara penuh terencana pada akhir tahun produksi.

\subsection{Tahapan-tahapan pemeriksaan dan proses pengecekan}

Tahapan-tahapan pemeriksaan dan pengecekan terhapan komponen-komponen unit ketel uap (boiler) di PT. Beurata Subur Persada dilakukan secara mingguan terdiri dari beberapa tahapan:
a. Pengecekan blowdown pada water drum apabila TDS tinggi.
b. Pengecekan shoot blowing.
c. Pengecekan ruang dapur kerak.

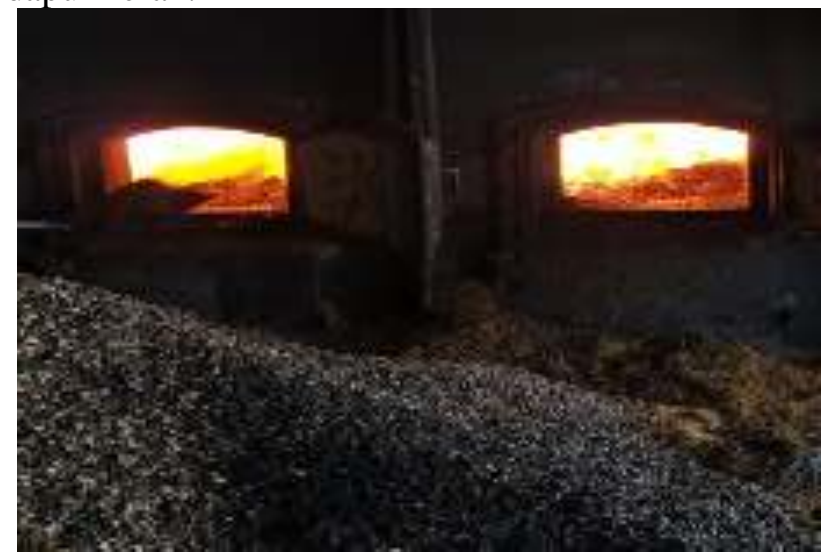

Gambar 4. Ruang dapur kerak[1]. 
d. Pengecekan safety valve.

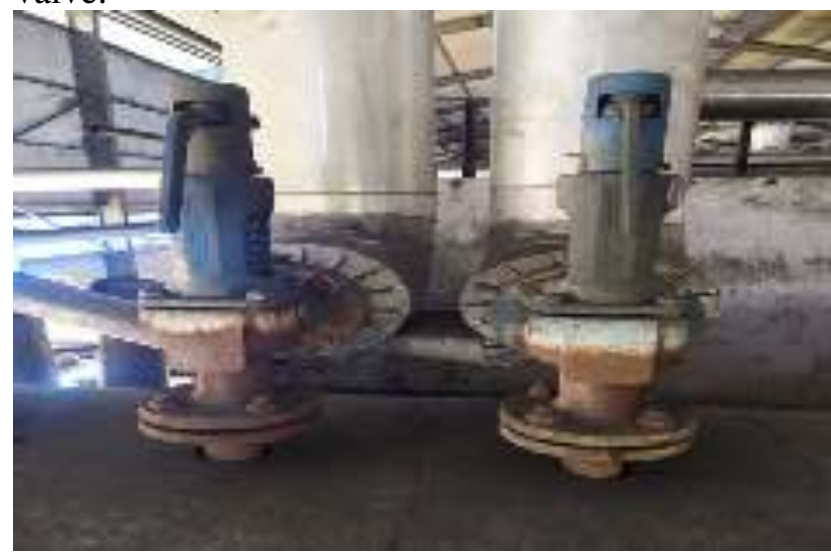

Gambar 5. Komponen safety valve[1].

e. Pengecekan pelumasan gear motor.

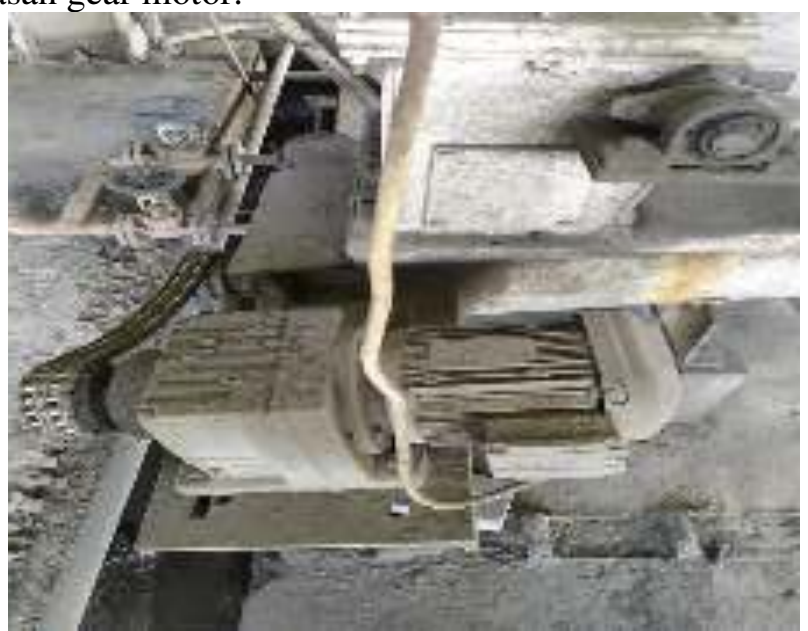

Gambar 6. Komponen gear motor[1].

f. Pengecekan kumpulan abu pada saluran gas, hopper dan impeler ID fan.

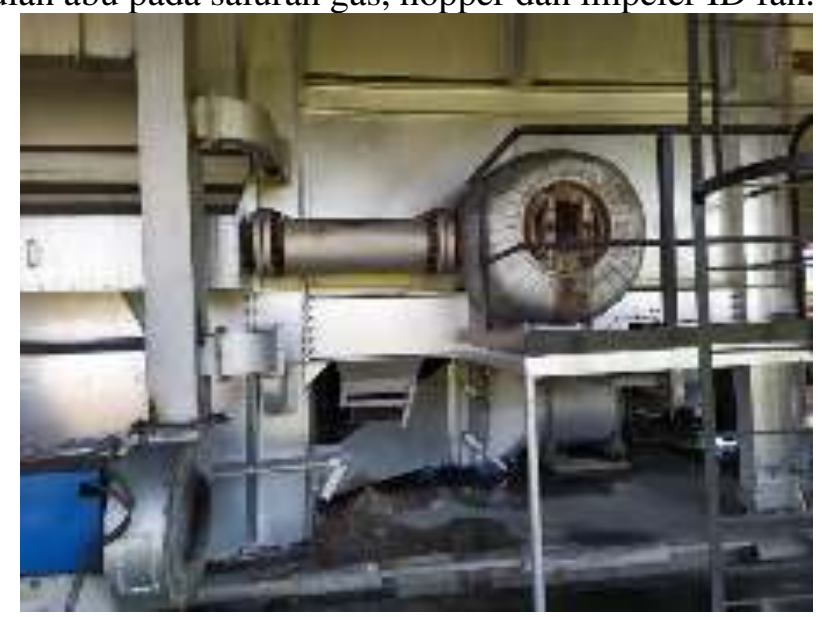

Gambar 7. Komponen ask hopper[1].

g. Pengecekan getaran pompa dan fan.

h. Pengecekan pelumas. 


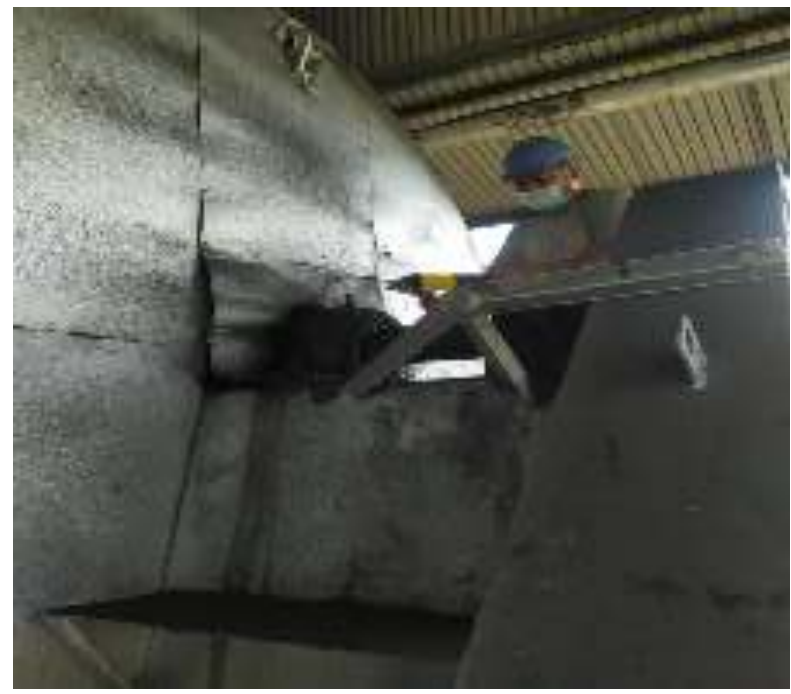

Gambar 8. Proses penambahan pelumas[1].

i. Pengecekan casing.

j. Pengecekan bearing, V-Belt dan baut-baut.

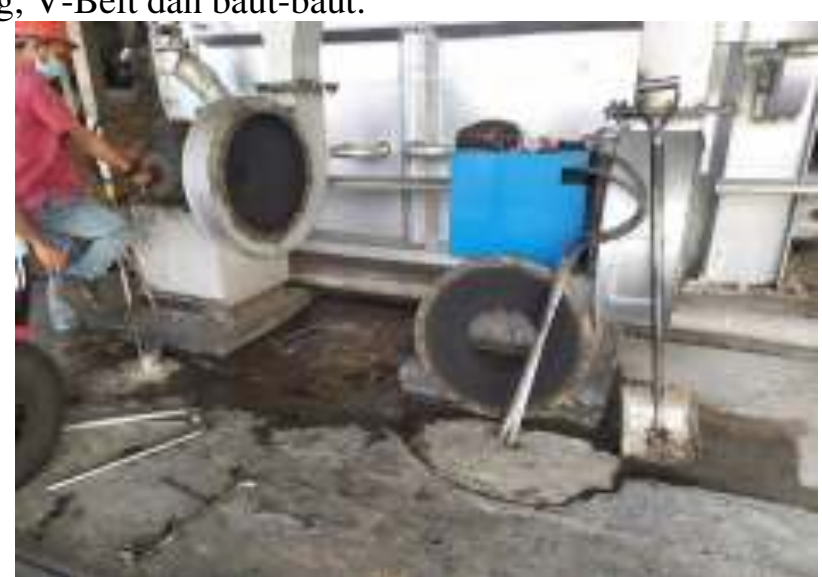

Gambar 9. Proses pengecekan bearing secondary air fan[1].

\section{KESIMPULAN}

Dari penelitian ini dapat diambil beberapa kesimpulan diantaranya dari hasil observasi dan wawancara terhadap karyawan PT. Beurata Subur Persada, maka proses perawatan di pabrik kelapa sawit tersebut lebih cocok diterapkan dengan metode perawatan terencana (planned maintenance). Adapun tahapan-tahapan dari proses perawatan terencana ini lebih rinci lagi terbagi kedalam preventive maintenance dan corrective maintenance. Langkah-langkah selanjutnya pada proses perawatan terencana tersebut diantaranya inspeksi (pemeriksaan), service, pergantian komponen dan overhaul.

\section{SARAN}

Adapun saran-saran yang dapat diberikan yaitu pada penelitian-penelitian selanjutnya perlu ditambahkan untuk metode-metode perawatan lainnya, sehingga diharapkan bisa menambah daya guna dari ketel uap (boiler) di pabrik tersebut. 


\section{DAFTAR PUSTAKA}

[1] "Beurata Subur Persada - Nagan Raya Palm Oil Mill." [Online]. Available: https://www.industryabout.com/country-territories-3/1937-indonesia/vegetable-oilindustry/30118-beurata-subur-persada-nagan-raya-palm-oil-mill. [Accessed: 20-Jun2020].

[2] E. Y. Setyawan and E. P. Tarigan, "Analisa Perawatan Ketel Uap Takuma N-600SA Menggunakan Metode FMEA , ANOVA dan RBD di PT . Perkebunan Nusantara III," Energy, vol. 8, no. 2, pp. 8-14, 2018.

[3] S. A. Muin, "Pesawat-pesawat konversi energi I : ketel uap / Syamsir A. Muin," 1988.

[4] "Rekomendasi Manajemen perawatan industri.by.Fajar Kurniawan. terbaru \& terlengkap | Tokopedia." [Online]. Available: https://www.tokopedia.com/rekomendasi/692826981?ref=googleshopping\&c=82589120 $57 \& m=127998088 \& \mathrm{p}=692826981 \& \mathrm{gclid}=$ EAIaIQobChMI1OK5n46T6gIV2DUrCh1 Au A-8EAYYASABEgIPK_D_BwE\&gclsrc=aw.ds. [Accessed: 21-Jun-2020].

[5]中牟田誠 and 国府島庸之, “Jurnal Kajian Manajemen Bisnis,” vol. 109, no. 4, pp. 555562, 2012, doi: 10.2403/jkmb.10885100.

[6] "CLICK HERE FOR DOWNLOAD Description: For courses in Operations Management."

[7] I. P. S. Ahuja and P. Kumar, "A case study of total productive maintenance implementation at precision tube mills," J. Qual. Maint. Eng., vol. 15, no. 3, pp. 241258, Aug. 2009, doi: 10.1108/13552510910983198.

[8] H. Rachman, A. K. Garside, and H. M. Kholik, "Usulan Perawatan Sistem Boiler dengan Metode Reliability Centered Maintenance (RCM)," J. Tek. Ind., vol. 18, no. 1, p. 86, 2017, doi: 10.22219/jtiumm.vol18.no1.86-93.

[9] B. Dhillon, "Maintainability, Maintenance, and Reliability for Engineers," Maint. Maintenance, Reliab. Eng., pp. 1-8.

[10] P. Preventive, M. Mesin, N. Fadilah, D. F. Aksioma, F. Matematika, and S. Data, "Optimasi Penentuan Waktu Optimum Menggunakan Metode Geometric," vol. 7, no. 2, pp. 40-45, 2018.

[11] "SISTEM PEWRAWATAN TERPADU (INTEGRATED MAINTENANCE SYSTEM) - PDF Download Gratis.” [Online]. Available: https://docplayer.info/30433847-Sistempewrawatan-terpadu-integrated-maintenance-system.html. [Accessed: 22-Jun-2020]. 